

\section{Years of Ecotoxicology since Silent Spring - A Review}

Silent Spring has been instrumental in starting off the field of ecotoxicology. Reviewing the development of environmental regulations as well as pesticide risk assessment, we show that although much progress has been made in evaluating the risk of chemicals in the environment, many challenges, like assessing mixture toxicity or sub-lethal impairment, still remain. Moreover, new pressing issues, like nanomaterials, have emerged.

Inge Werner, Bettina Hitzfeld

50 Years of Ecotoxicology since Silent Spring A Review

GAIA 21/3 (2012): 217-224

\begin{abstract}
In her book Silent Spring, Rachel Carson describes the catastrophic effects of the indiscriminate use of pesticides in the 1940s and 1950s. These substances, most of them insecticides, have since been designated as persistent organic pollutants and are regulated nationally and internationally. They have subsequently been replaced by less persistent yet highly toxic compounds. The experience gained in those decades triggered environmental regulation and risk assessment schemes. The ecotoxicological tests required for risk assessment greatly advanced the development of new concepts and tools in this field. Today, we are no longer faced with disastrous poisonings such as those described in Silent Spring. Nevertheless, the same compounds are still present in the environment adding to the increasing number of chemicals organisms must cope with. Many ecotoxicological questions remain to be solved and new ones have emerged regarding, eg., the effects of nanomaterials, the phenomenon of bee colony collapse disorder, and the consequences of climate change.
\end{abstract}

\section{Keywords}

environmental regulation, pesticides, persistent organic

pollutants (POPs), risk assessment

Contact: Dr. Inge Werner | Center for Applied Ecotoxicology | Eawag | BU F 15-19 | Überlandstr. 133 | 8600 Dübendorf | Switzerland | Tel.: +41 448235121 | E-Mail: inge.werner@oekotoxzentrum.ch

Dr. Bettina Hitzfeld | Federal Office for the Environment | Air Pollution Control and Chemicals Division | Bern | Switzerland | E-Mail: bettina.hitzfeld@bafu.admin.ch

C 2012 I. Werner, B. Hitzfeld; licensee oekom verlag. This is an Open Access article distributed under the terms of the Creative Commons Attribution License (http://creativecommons. org/licenses/by/3.0), which permits unrestricted use, distribution, and reproduction in any medium, provided the original work is properly ated.
The entry "ecotoxicology" in Wikipedia states: "The publication in 1962 of Rachel Carson's seminal volume, Silent Spring, catalysed the separation of environmental toxicology ${ }^{1}-$ and, subsequently, ecotoxicology ${ }^{2}$ - from classical toxicology. The revolutionary element in Carson's work was her extrapolation from single-organism effects to effects at the whole ecosystem and the "balance of nature" (Wikipedia 2011).

Carson describes the catastrophic effects of the insecticide dichlordiphenyltrichlorethane (DDT) and other pesticides often used in agricultural control programs in the 1940s and 1950s. They belong to a group of persistent organic pollutants (POPs) that is now widely known as the "dirty dozen":

- aldrin, chlordane, DDT, dieldrin, endrin, heptachlor, mirex, toxaphene (insecticides),

- polychlorinated dibenzo-p-dioxins and polychlorinated dibenzofurans (PCDDs/PCDFs) (combustion by-products from, e.g., waste incineration or the metallurgic industry),

- hexachlorobenzene (insecticide, industrial chemical and combustion by-product), as well as

- polychlorinated biphenyls (PCBs) (industrial chemicals and combustion by-products).

Since the 1960s, environmental laws have taken effect in many nations, an entire new research discipline has emerged, and tools to detect and predict the hazards and risks of environmental contaminants have been developed. But how far have we come in our efforts to prevent the toxic impacts of pesticides, especially insecticides, and other man-made chemicals in the environment? Can we detect and prevent the consequences of increasing numbers and quantities of chemicals in our environment? 50 years after Silent Spring, it is time to take a look at the state of ecotoxicology.

\footnotetext{
1 "Environmental toxicology" is the study of harmful effects of chemicals on living organisms (Newman and Unger 2003).

2 "Ecotoxicology" is the study of harmful effects of chemicals on ecosystems
} (Walker et al. 2001). 


\section{Pest Control: A Brief History of Insecticides - from DDT to Pyrethroids}

\author{
There are vast gaps in our knowledge of how dieldrin is \\ stored or distributed in the body or excreted, \\ for the chemists' ingenuity in devising insecticides has \\ long ago outrun biological knowledge of the way \\ these poisons affect the living organism.
}

Rachel Carson (1979, p. 39) ${ }^{3}$

When Carson wrote her book, the production of synthetic pesticides in the United States (US) had soared from 56362 tons of active pesticide ingredients in 1947 to 289240 tons in 1960 - more than a fivefold increase. By 1993, an estimated 500000 tons were used in the US annually, and 2000000 tons worldwide (Winston 1999). In the European Union (EU 15), 327642 tons were sold in 2001 (Eurostat 2001); almost 2300 tons were sold in Switzerland in 2008 (FOEN 2011). Most toxic among this large group of chemicals are the synthetic organic insecticides, which share the common property of damaging the nervous system of animals.

Most synthetic insecticides belong to a few distinct chemical groups, each with characteristic properties and toxic mechanisms. In the 1950s and 1960s, the vast majority fell into two large categories: the chlorinated hydrocarbons (or organochlorines) and organic phosphorous compounds (or organophosphates, OPs).

The most prominent organochlorine, DDT, and a number of related compounds bioaccumulate, due to their stability and fat solubility in the organisms' fatty tissues. In addition, they may biomagnify, which causes progressively higher concentrations in animals higher up the food chain. Besides, they interfere with the reproductive systems of birds and other vertebrates. One of the better known environmental impacts of DDT (or rather its metabolite, dichlorodiphenyldichloroethylene, DDE) is to reduce the thickness of egg shells in predatory birds, which caused severe reductions in bird populations (e. g., Hickey and Anderson 1968). The ban on agricultural use of DDT and related chemicals in 1972 (e. g., Germany, Switzerland, and US) has allowed some species, such as the brown pelican, to recover in recent years (US DOI 2009). Worldwide these chemicals have been regulated via the Stockholm Convention on Persistent Organic Pollutants since 2004 (Stockholm Convention 2004). Under this convention the use of DDT is allowed solely under specific conditions (inter alia compliance with World Health Organization [WHO] recommendations) for the control of mosquitoes (Anopheles sp.) carrying the malaria parasite. Lindane and endosulfan have been banned since 2009 and 2011, respectively; however, they can still be applied for control of head lice (lindane) or for specific crop-pest combinations for which a party to the Stockholm Convention has applied for an exemption (endosulfan).

OP insecticides, the second group, include compounds like malathion, diazinon, and chlorpyrifos, which were initially developed and used as deadly nerve gases during World War II. Since then, these chemicals have been widely applied as insecticides in agricultural and urban pest as well as disease control. The OPs are less persistent but more toxic than organochlorines. Because of their potential for causing toxicity in humans, especially children, some of the most commonly used OPs were ultimately banned in several countries: Parathion was banned in the US in 2000 and in the EU in 2001. In 2001 the US Environmental Protection Agency (USEPA) placed new restrictions on the use of the OPs phosmet and azinphos-methyl to increase protection of agricultural workers, and residential use of diazinon and chlorpyrifos was phased out in 2003 to 2004 . Nevertheless, both are still registered for use in most countries. To this day, OPs and their less toxic "cousins", the carbamates, are among the most widely applied groups of insecticides in the world (Eurostat 2001, CDPR 2010).

The ban on certain uses of OP insecticides as well as the emergence of resistant insects has since led to their gradual replacement with other classes of insecticides, among them neonicotinoids and pyrethroids. Both are derivatives of natural compounds, nicotine and pyrethrin, which have long been used as natural insecticides. Modern synthetic insecticides are far less persistent than organochlorines and less toxic to mammals than OPs, but non-target invertebrates and fish can be susceptible at extremely low concentrations. This poses new challenges for detection and regulation. For example, pyrethroids can cause acute toxic effects to aquatic invertebrates below five nanograms per liter (Werner and Moran 2008), concentrations that are difficult to measure. Their input into aquatic ecosystems has long been assumed to be negligible (due to their chemical properties) until recent studies demonstrated that toxic amounts were present in water and sediment of surface waters (Weston et al. 2005, Amweg et al. 2006); as a consequence the California Department of Pesticide Regulation reevaluated their registration status in California (CDPR 2006). In spite of this, pyrethroids continue to be widely used in the US and elsewhere ${ }^{4}$ for urban as well as agricultural application. In 2010 a total of 294.3 tons (active ingredient) of the two most common pyrethroids, permethrin and bifenthrin, were applied commercially in California alone (CDPR 2010). For the majority of countries, such use data is not publicly available.

\section{Current Approaches for Protecting the Environment}

\section{Regulation and Risk Assessment}

Manufacturers' tests on the common laboratory animals - (...) include no wild species, no birds as a rule, no fishes, and are conducted under controlled and artificial conditions. Their application to wildlife in the field is anything but precise.

Rachel Carson (1979, p. 119)

3 Silent Spring was first published by Houghton Mifflin, Boston, in 1962. For the relevance of Silent Spring in a historical perspective see Mauch (2012, in this issue).

4 In the EU, cypermethrin and bifenthrin are registered while the use of permethrin is no longer allowed. 
Plant protection products (PPPs) are the chemicals that have been regulated the longest. In the EU, PPPs may only be sold and used after they have been shown to not have harmful or unacceptable effects on humans or the environment, and to be sufficiently effective. From 1991 until 2011, this was regulated under Directive 91/414/EEC(D 91/414/EEC 1991). The review process under this directive identified 1000 active ingredients on the European market. Of these, only 26 percent have subsequently been approved for use, 67 percent were removed from the market due to withdrawal by industry or incomplete dossiers, seven percent (about 70 substances) failed the review and were removed from the market as no safe use could be shown (European Commission 1993). To perform this assessment, the directive prescribes ecotoxicological tests in its "uniform principles for the evaluation and authorisation of PPPs". Here effects of the active ingredient and the product are tested on non-target species using standardized test protocols, and then compared with a predicted exposure concentration (figure 1).

So-called toxicity/exposure ratios (TER) for both short- and long-term exposure are determined that should not exceed certain trigger values. For example, the ratio between toxicity and exposure for fish and Daphnia magna (figure 2, p. 220) under acute exposure conditions should not be below 100 (i.e., the predicted concentration of the PPPs in the environment must not exceed 0.1 microgram per liter, if the measured acute toxic effect concentration in fish is ten micrograms per liter or lower).

In the case of birds and mammals, exposure occurs often via food, granules, seeds or water as well as preening, thus these exposure routes are considered in risk assessment. Secondary poisoning, bioaccumulation, biomagnification, and endocrine effects are also taken into account. In the application of the directive, guidance on risk assessment procedures for birds and mammals as well as for aquatic and terrestrial species was developed. This has had a great impact on the development of ecotoxicological tests and concepts.

New regulation on PPPs has come into force in the EU in 2011 that introduced hazard based cut-off criteria: PPPs must not have CMR (carcinogenic, mutagenic or reprotoxic), POP (persistent organic pollutant), $\mathrm{PBT}$ (persistent, bioaccumulative, toxic) or vPvB (very persistent, very bioaccumulative) characteristics or cause endocrine disruption (Regulation[EC] No1107/2009). ${ }^{5}$ The development of these criteria and their application as a "no-go" in the registration process of PPPs are crucial steps towards the protection of the global environment and human health, however, it is quite apparent that the concerns raised by Rachel Carson are still relevant today.

5 In contrast, industrial chemicals with PBT properties are not completely banned in the EU but have to be registered according to Registration, Evaluation, Authorisation and Restriction of Chemicals (REACH) (Scheringer 2012, in this issue). PPP regulation is stricter than REACH as PPPs are brought directly into the environment under normal use conditions. This is effective under Regulation (EC) No 1107/2009 when new active substances are to be registered.

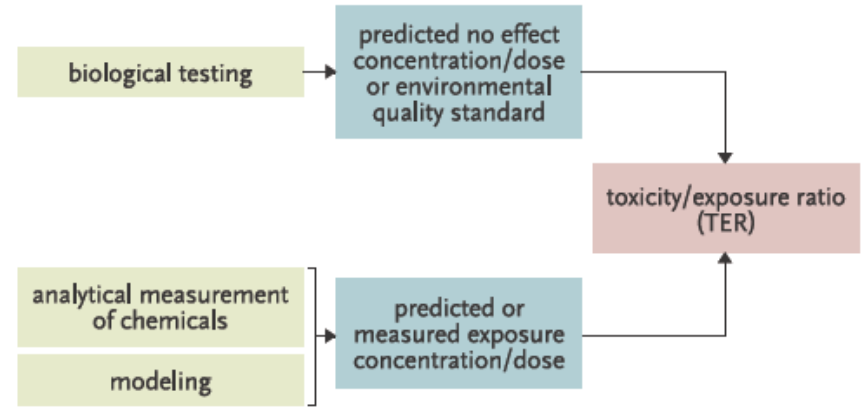

FICURE 1: The components of environmental risk assessment. Both biological effect thresholds and exposure concentration and routes are considered when deriving toxicity/exposure ratios.

\section{Effect-Based Environmental Criteria}

In rivers, a really incredible variety of pollutants combine to produce deposits that the sanitary engineers can only despairingly refer to as "gunk".

Rachel Carson (1979, p. 51)

Effect (or hazard) based environmental quality standards (EQS) or criteria have been used since the 1970s, after the US Water Quality Act of 1965 required the development of numeric criteria for the protection of human health (Water Quality Act 1965). With the enactment of the Clean Water Act in 1977, the philosophy of water pollution control in the US shifted (Clean Water Act 1977). It became a national policy that "the discharge of toxic pollutants in toxic amounts be prohibited". Thus EQS became valuable tools to assess the risk of individual chemicals in the aquatic environment. In the EU, the Water Framework Directive (WFD) drives the derivation of EQS (WFD 2000). The WFD aims to ensure the good chemical status of both surface water and groundwater bodies across Europe. The WFD describes the strategy for the establishment of harmonized quality standards and emission controls for priority substances posing a significant risk to, or via, the aquatic environment.

Such EQS are an important tool for achieving the protection goals. However, their usefulness in assessing the combined effects of chemicals and other stressors (physical, biological) and of chemical mixtures is limited. In addition, the ability to derive EQS for all pesticides of interest - which would be costly but not impossible - is often hampered by the lack of effect data, and in some cases, such as for pyrethroids, analytical detection limits may not be as low as concentrations where toxic effects can occur. The difficulties to regulate such compounds are significant as present environmental laws rely heavily on analytical data.

\section{Biological Tools}

We are accustomed to look for the gross and immediate effect and to ignore all else. (...) The lack of sufficiently delicate methods to detect injury before symptoms appear is one of the great unsolved problems in medicine. 
Long before the onset of environmental regulation, biological tools based on indicator species were used to detect environmental hazards, such as the "canary in the coal mine" used to warn miners of dangerous levels of carbon monoxide and methane. Standardized biological methods to measure water quality developed quickly after the US EPA initiated a national policy in 1984 to control toxic substances based on a water quality approach. The issuance of permits for effluent discharges into surface waters was subsequently tied to whole effluent testing using standardized toxicity tests. ${ }^{6}$ Such tests enable the direct measurement of toxicity independent of the number of causative chemicals or mixture effects. In addition, aquatic community indices such as the saprobic (Kolkwitz and Marsson 1909) or SPEAR (SPEcies At Risk) indices (Liess et al. 2008) integrate the effects of all chemical, physical, and biological stressors acting in a system. Bioassays can measure mechanism-specific (in vitro) or integrative (in vivo) toxic effects and provide the data needed for the derivation of EQS. The measurement of toxic effects due to low-level, pseudo-persistent contamination or intermittent exposure to pollutants, however, poses new challenges in monitoring, especially where predictive indicator tools are required. Technological advances in biochemistry and molecular biology increasingly enable us to refine these tools, but many gaps in our ability to diagnose the health of organisms or ecosystems remain (see also Challenges below) due to temporal and financial restrictions that are necessarily present when using bio-

FIGURE 2: The waterflea, Daphnia magna, is one of the most sensitive indicator organism for the toxic effects of insecticides in the aquatic environment.

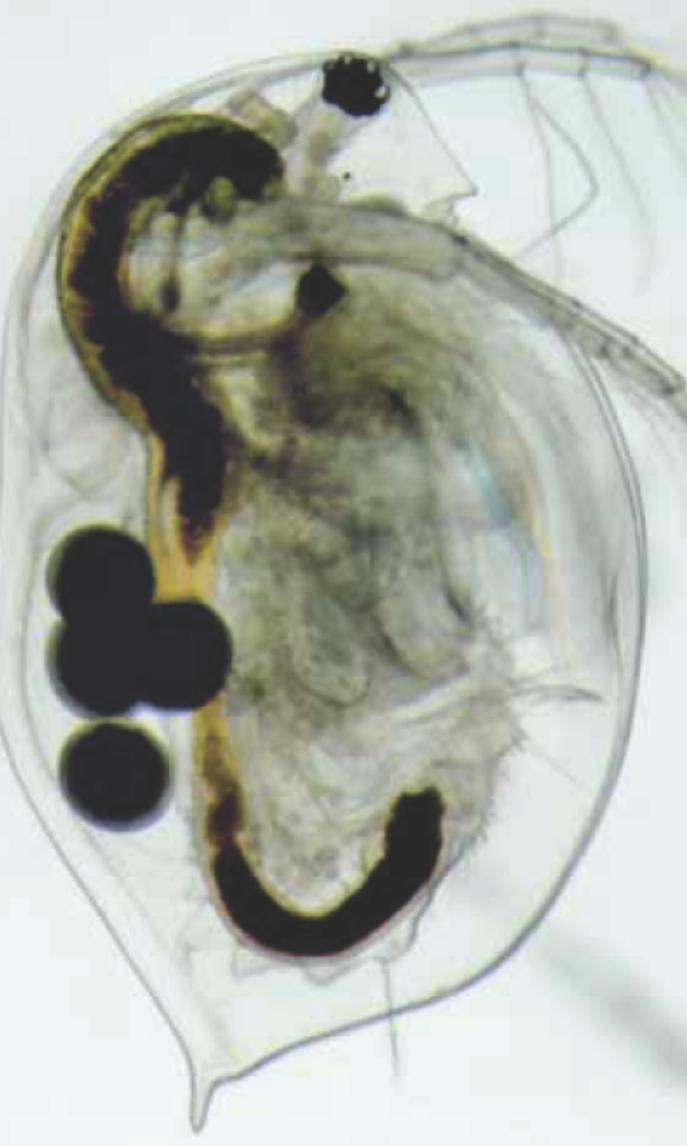

assays in regulatory and scientific investigations: 1 . Standardized test systems rely on measuring responses in model species that may not be representative of more vulnerable species. 2. Likewise, toxicity endpoints (parameters quantified in toxicity tests) that can easily be measured in laboratory settings may ignore many of the intricate, more sensitive functions or species interactions that are essential for the ecological fitness of an organism and populations. Molecular techniques looking at changes in gene expression or proteins (e. g., toxicogenomics and proteomics) hold much promise, and will likely become an essential aspect of any biomarker portfolio developed for resident species in the near future, especially because of their versatility in studying different species and endpoints. The potential power of these methods is already being demonstrated in management (Ankley et al. 2006), and international standardization efforts are underway. There is, however, a great need for studies linking molecular responses to higherlevel effects such as growth, reproduction, and survival, so that results can be interpreted in an ecological context (Fedorenkowa et al. 2010). The promising concepts of "adverse outcome pathways (AOP)" (Kramer et al. 2011) and systems biology (GarciaReyero and Perkins 2011) aim at establishing these linkages, however, integration of such concepts into hazard or risk assessment will require the standardization of methods (Van Aggelen et al. 2010). From this it may seem that community indices would currently be the most integrative and the most meaningful parameters to monitor the consequences of toxic chemicals in the environment, but such indices often do not allow an identification of the causative agents. Many field studies, therefore, result in the conclusion that multiple stressors are causing a negative impact at the population level. Despite 50 years of research and many more tools at our disposal, our ability to measure and detect or even predict the impact of toxic chemicals in our environment is still insufficient.

\section{Challenges in Assessing the Environmental Impacts of Chemicals}

Just like when Carson rang the alarm bells, insecticides and other pesticides continue to pose a significant threat to surface water quality. Although their application has become less careless and the compounds less persistent, they have become an essential part of our modern world and still enter our natural environment in considerable amounts.

\section{The Toxic Effects of Chemical Mixtures}

Another almost unexplored area is the question of interactions between chemicals, (...) All of these questions urgently require the precise answers that only extensive research can provide, yet funds for such purposes are pitifully small.

Rachel Carson (1979, p. 141) 
In the 1990 s, a US-survey showed that over 50 percent of more than 4000 stream water samples contained six or more pesticides (Gilliom et al. 1999). Such chemical mixtures must be considered to be the most common exposure scenario in the environment. To date, however, regulatory requirements on risk assessments of chemicals are largely based on individual substances. It was only within the last decade that broad interest in the need for assessing the risks of combined exposure to multiple substances started to mount. Available approaches for assessing the toxicity of chemical mixtures include mathematical models (Backhaus and Faust 2012) and biological tools (figure 3, see also Biological Tools above). Only well-defined mixtures can be assessed using the two classical mathematical models: concentration addition (mixture ingredients have the same mechanism of action) and independent action (mixture ingredients have different mechanisms of action). Biological tools allow quantification of the combined effects of chemical mixtures even if ingredients are unknown; however, the choice of test species and endpoints is crucial for obtaining meaningful data. Where in vitro methods exist to quantify specific toxic effects, e.g., inhibition of the enzyme acetylcholine esterase in nerve cells (by OPs and carbamates) or of photosynthesis in algal cells (primarily by herbicides), effects can be expressed as toxicity equivalents normalized to a reference substance, which allows comparison across mixtures containing different concentrations and chemicals (Escher et al. 2008).

Multiple regulatory agencies (e.g., the European Food Safety Agency [EFSA], US EPA, and UK Intergovernmental Group on Health Risks from Chemicals) have recently issued or updated guidance documents for addressing mixture toxicity assessment. In 2009 the EU Council asked the EU Commission to advise on the adequacy of current legislation for addressing the toxicology of mixtures and to propose appropriate guidance(Kortenkamp et al. 2009). A WHO International Programme on Chemical Safety (IPCS) framework for risk assessment of combined exposures to multiple chemicals was presented at a workshop of WHO, Organization for Economic Cooperation and Development (OECD), and International Life Sciences Institute - Health and Environmental Sciences Institute (ILSI-HESI) in 2010 (Meek et al. 2011). Its application in the regulatory process will be a great step forward in evaluating the risks of chemical mixtures in the environment.

\section{Chronic Poisonings \\ Because these small amounts of pesticides are cumulatively stored and only slowly excreted, threat of chronic poisoning and degenerative changes of the liver and other organs is very real.}

Rachel Carson (1979, p. 36)

There is a wide range of possible contaminant effects that can compromise the ecological fitness of individual organisms or a population. Ultimately, the impact a toxic contaminant or contaminant mixture may have depends on, most importantly, the relative sensitivity of the species as well as the intensity and timing of exposure. Acutely toxic events, most visibly fish kills, that were relatively common a few decades ago, are now rarely observed.
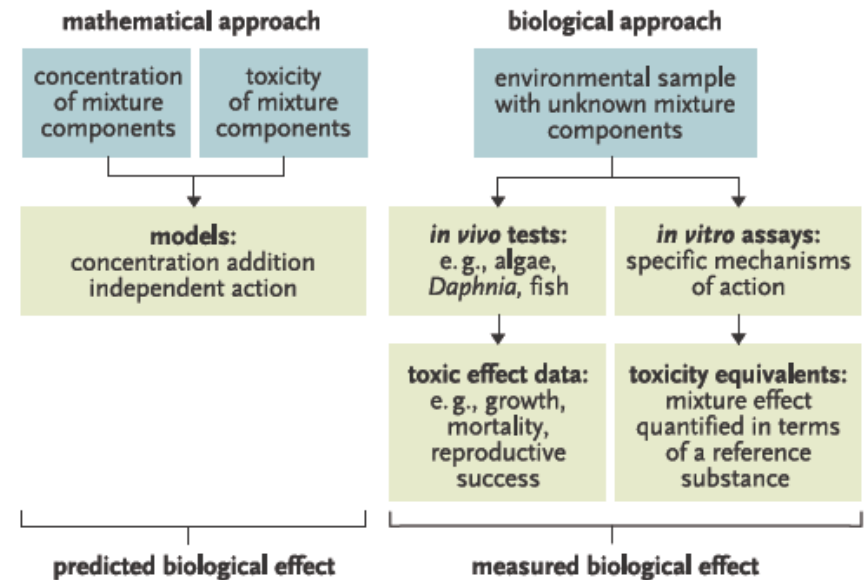

FICURE 3: Current approaches to measure or predict the combined effects of chemical mixtures. Mathematical models require both exposure and effect data to predict toxicity, while biological methods measure toxicity directly.

However, chronic effects in the form of sub-lethal damage to organisms can be observed at concentrations found in the environment. These include impairment of the reproductive (Sumpter 2005) or immune system (Arkoosh et al. 2001), and genetic (Shugart 1995), developmental, and behavioral changes (Weis and Weis 1995, Sandahl et al. 2007). They can severely reduce ecological fitness and ultimately survival, since the individual must be able to successfully compete with others for food, avoid predation, reproduce, and cope with pathogens and other environmental stressors. Such effects are not easily detected and can act for long periods of time before being recognized.

Endocrine disruption is a very prominent example of such sublethal effects: endocrine disrupting chemicals (EDCs) interfere with the normal functioning of the endocrine system. Exposure to extremely low concentrations can impede gonadal function, reduce fertilization success, decrease fecundity, and alter mating behavior (Sumpter 2005, Martinovic et al. 2007) in aquatic species. One of the more potent estrogens found in surface waters is 17 alpha-ethinylestradiol (the synthetic estrogen used in birth-control pills). This compound, like natural estrogens, is not completely removed by sewage treatment plants (Johnson and Williams 2004), and can cause the collapse of fish populations at trace concentrations of lower than six nanograms per liter (Kidd et al. 2007). Other known EDCs include industrial chemicals and waste products, such as PCDDs, PCDFs and PCBs, organochlorine and pyrethroid pesticides (and their metabolites), surfactants, as nonylphenol polyethoxylates used in pesticide formulations, and phthalates used in plastic products (Scheringer 2012, Langston 2012, both in this issue). Despite decades of research, no water or sediment quality criteria currently exist for protecting human and aquatic life against endocrine disruption and its related effects.

\section{Laboratory to Environment Extrapolation}

Campus earthworms had been fed inadvertently to crayfish in a research project and all the crayfish had promptly died.

$$
\text { Rachel Carson (1979, p. 62) }
$$


In the past, serious environmental threats caused by pollutants have primarily been brought to light as a result of observing severe biological effects in the field. Examples include DDE and eggshell thinning in birds (Hickey and Anderson 1968), sex changes in freshwater fish associated with EDCs (Vos et al. 2000), and tumors in marine fish associated with polycyclic aromatic hydrocarbons (Baumann and Harshbarger 1995). In order to prevent such ecological damage before it occurs, there is an urgent need for techniques that detect the less obvious sub-lethal impairment that might ultimately result in population level effects (Depledge and Galloway 2005).

Effectively linking the effects of pollutants in laboratory bioassays through the various hierarchical levels of biological organization to ecosystem and potentially human health requires a pragmatic integrated approach based on existing data that either links or correlates processes of pollutant uptake, detoxification and pathology with each other and higher level effects (Depledge 2009). Portfolios of carefully selected biological indicators, including laboratory bioassays, analysis of biomarkers - molecular, biochemical, cellular, and physiological alterations caused by external stressors (Van der Oost et al. 2003, Forbes et al. 2006) - in species of concern, field studies, and a thorough understanding of organismal function, species interactions as well as the influence of additional physical and biological stressors (e.g., disease, food depletion) are required to evaluate toxicity and assess the risk to ecosystems. New information on toxic mechanisms and biological approaches (e.g., AOPs) hold much promise in this regard, but the level of uncertainty in predictions will remain high in the foreseeable future. Application of the "precautionary principle" (EEA 2001) will therefore be needed for some time.

\section{Burning Topics}

\section{Nanomaterials}

What are the effects?

Rachel Carson (1979, p. 208)

Nanomaterials have special properties due to their nanoscale dimensions. They are defined as materials with a particle size less than 100 nanometer in at least one dimension. Thus their toxicological properties might be different than that of "classical" particles or substances. Manufactured nanomaterials are in use in a multitude of products, including pesticides (Khot et al. 2012). Their uses bring benefits but their risks have until now not been fully understood. New regulations will require information on the ecotoxicological effects of nanomaterials. The development of adequate test methods is currently one of the big challenges for ecotoxicologists.

\section{Bee Colony Collapse Disorder}

But in May of that year this man lost 800 colonies after the state had sprayed a large area. (...) Another beekeeper, whose 400 colonies were incidental targets of the 1957 spray, reported that 100 per cent of the field force of bees (...) had been killed in forested areas and up to 50 per cent in farming areas sprayed less intensively. "It is a very distressful thing," he wrote, "to walk into a yard in May and not hear a bee buzz".

Rachel Carson (1979, p. 146)

The "pollinator crisis" or the "colony collapse disorder" has been one of the biggest environmental concerns in recent years (UNEP 2010, SETAC 2011). Pollinators play a central and crucial role in the boosting of reproduction of wild plants and in fruit production of many commercial crops. The value of the pollination service rendered by managed pollinating species such as the honeybee, Apis mellifera, has been estimated to be in the order of 22.8 to 57 billion Euros. An unusual reduction in managed honeybee colony numbers has been observed since 1998 in many European countries, North America, China, and North Africa. The causes for this decrease have not yet been elucidated completely and are probably multifactorial (the UN report identifies habitat destruction, increased pathologies, invasive species, and pollution). Pesticides have been implicated by many studies, among them herbicides, broad-spectrum as well as systemic insecticides, such as the neonicotinoids used in seed treatment (EFSA 2012, Henry et al. 2012).

\section{POPs Are Still with Us}

To find a diet free from DDT and related chemicals, it seems one must go to a remote and primitive land, still lacking the amenities of civilization. Such a land appears to exist, at least marginally, on the far Arctic shores of Alaska although even there one may see the approaching shadow. When scientists investigated the native diet of the Eskimos in this region it was found to be free from insecticides. (...) There was only one exception - two white owls from Point Hope carried small amounts of DDT, perhaps acquired in the course of some migratory journey.

Rachel Carson (1979, p. 163)

While Carson described the Arctic as free from contamination of organochlorine pesticides, she recognized that the contaminants might eventually enter these remote regions and foresaw one of the possible pathways via migratory species. Nowadays, we know that the Arctic (and Antarctic) is not "free from DDT and related chemicals" and recognize that these regions and the Inuit people are especially vulnerable due to the long-range transport and biomagnification properties of POPs (Scheringer 2012, in this issue). 42 years after Carson's description of their effects on wildlife, POPs have been prohibited globally for production and use since 2004 (Stockholm Convention 2004). To date, 177 countries are parties to the Stockholm Convention, and in 2009 and 2010 ten POPs were added to the list (see Stockholm Convention 2004 for further details). The international community has thus banned a total of 22 substances with POP properties. However, the identification of additional POPs still in use today and the global monitoring of banned POPs remain challenges for both the scientific and regulatory communities. 


\section{Climate Change}

The amount of food available, conditions of weather and climate, the presence of competing or predatory species, all are critically important.

Rachel Carson (1979, p. 215)

The expected impacts of climate change on the toxicological and ecotoxicological effects of POPs have recently been described in an expert group report by the United Nations Environment Programme (UNEP) and the Arctic Monitoring and Assessment Programme (AMAP) (UNEP/AMAP 2011). Climate change can affect the environmental fate of chemicals in many ways, most notably through the intensity of storms and changes in abiotic parameters, such as temperature, salinity, $\mathrm{pH}$, and UV radiation. In turn, these factors can modify uptake, metabolism and toxicity of chemicals and alter trophic structures and interactions as well as physiological and behavioral adaptation mechanisms. The report concludes that it is uncertain in which animal or human populations or regions the toxic effects of POPs will increase or decline as a result of climate change.

\section{Are Pesticides Safer Today?}

A few minutes' research in any supermarket is enough to alarm the most stouthearted customer - provided, that is, he has even a rudimentary knowledge of the chemicals presented for his choice. The display is homey and cheerful, and, with the pickles and olives across the aisle and the bath and laundry soaps adjoining, the rows upon rows of insecticides are displayed.

Rachel Carson (1979, p. 158)

50 years ago, concerns over pesticide effects on human health and the environment were largely focused on organochlorine insecticides. Compared to today, the number of chemicals under consideration was low and their toxic effects in the environment were obvious. The highly persistent chemicals were measurable in sediments and tissues making it possible to track their movement to the current day. After their ban in the US, the number and diversity of pesticide products greatly expanded. Organophosphates and others are by design less persistent than the "legacy pesticides" and many are difficult to measure at concentrations toxic to aquatic organisms (Kuivila and Hladik 2008). Indirect effects on fish and other predators via food depletion (phyto- and zooplankton) can be important factors in population dynamics. Modern pesticides are highly effective and designed to disrupt the physiology of specific taxonomic groups; nevertheless, it has been nearly impossible to manufacture a pesticide that is selective for the target species yet nontoxic to other species, particularly closely related taxa. Thus, there is an enduring trade-off between the societal benefits of applying pesticides (e. g., increased agricultural production, reductions in vector-borne diseases) and minimizing unintended impacts on aquatic ecosystems and human health. Despite successes in improving water quality in many nations, surface waters today are still not providing healthy habitats for fish. Habitat degradation, including the effects of chemicals, and nonindigenous species were named as the main threats to at-risk fishes (Jelks et al. 2008). 50 years after Silent Spring, a significant number of issues related to the environmental effects of these chemicals remain to be solved. We have undoubtedly acquired more knowledge, but the complexity of ecosystem function still poses enormous challenges in our ability to predict, measure, and reduce the environmental risks of chemicals.

\section{References}

Amweg, E. L., D. P. Weston, J. You, M. J. Lydy. 2006. Pyrethroid insecticides and sediment toxicity in urban creeks from California and Tennessee. Environmental Science and Technology 40/5: 1700-1706.

Ankley, G. T. et al. 2006. Toxicogenomics in regulatory ecotoxicology. Environmental Science and Technology 40/13: 4055- 4065.

Arkoosh, M. R. et al. 2001. Increased susceptibility of juvenile chinook salmon to vibriosis after exposure to chlorinated and aromatic compounds found in contaminated urban estuaries. Joumal of Aquatic Animal Health 13:257-268.

Backhaus, T., M. Faust. 2012. Predictive environmental risk assessment of chemical mixtures: A conceptual framework. Environmental Science and Technology 46/5: 2564-2573.

Baumann, P.C., J.C. Harshbarger. 1995. Decline in liver neoplasms in wild brown bullhead catfish after coking plant closes and environmental PAHs plummet. Environmental Health Perspectives 103/2: 168-170.

Carson, R. 1979 (orig. 1962). Silent spring. Middlesex, UK: Penguin. CDPR (California Department of Pesticide Regulation). 2006. Reevaluation. www.cdpr.ca.gov/docs/registration/reevaluation/chemicals/pyrethroids. htm (accessed August 18, 2012).

CDPR. 2010. Pesticide use reporting database. www.cdpr.ca.gov/docs/pur/ purmain.htm (accessed July 10, 2012).

Clean Water Act. 1977. Clean Water Act of 1977. Public Law 95-217, December 27, 1977. United States Statutes at Large 91: 1566-1611.

D 91/414/EEC. 1991. Council Directive 91/414/EEC of 15 July 1991 concerning the placing of plant protection products on the market. Official Journal of the European Union L 230, 19.8.1991: 1-32.

Depledge, M. H. 2009. Novel approaches and technologies in pollution assessment and monitoring: A UK perspective. Ocean and Coastal Management 52: 336-341.

Depledge, M. H., T. S. Galloway. 2005. Healthy animals, healthy ecosystems. Frontiers in Ecology and Environment 3/5: 251-258.

EEA (European Environment Agency). 2001. Late lessons from early warnings: The precautionary principle 1896-2000. Copenhagen: EEA.

EFSA (European Food Safety Authority). 2012. Assessment of the scientific information from the Italian project "APENET" investigating effects on honeybees of coated maize seeds with some neonicotinoids and fipronil. EFSA Joumal 10/6: 2792-2818.

Escher, B., N. Bramaz, J.F. Mueller, P. Quayle, S. Rutishauser, E. L. M. Vermeirssen. 2008. Toxic equivalent concentrations (TEQs) for baseline toxicity and specific modes of action as a tool to improve interpretation of ecotoxicity testing of environmental samples. Joumal of Environmental Monitoring 10: $612-621$.

European Commission. 1993. Review programme of existing pesticides: Overview. http://ec.europa.eu/food/plant/protection/evaluation/rev_prog_exist_ pest_en.htm (accessed October 20, 2011).

Eurostat. 2001.Verkauf von Pflanzenschutzmitteln. appsso.eurostat.ec.europa.eu/ nui/show.do?dataset=food_in_apest 1 \&lang=de (accessed October 20, 2011).

Fedorenkowa, A., J. Arievonk, H. J. Roblenders, N. Joopouborg, A. Breure, A. Janhendriks. 2010. Ecotoxicogenomics: Bridging the gap between genes and populations. Environmental Science and Technology 44/11: 4328-4333.

FOEN (Federal Office for the Environment). 2011. Environment Switzerland 2011. Bern: FOEN. www.bafu.admin.ch/umwelt/10822/10823/index.html? lang=en (accessed October 28, 2011). 
Forbes, V. E., A. Palmqvist, L. Bach. 2006. The use and misuse of biomarkers in ecotoxicology. Environmental Toxicology and Chemistry 25/1:272-280.

Garcia-Reyero, N., E.J. Perkins. 2011. Systems biology: Leading the revolution in ecotoxicology. Environmental Toxicology and Chemistry 30/2: 265-273.

Gilliom, R. J., J. E. Barbash, D.W. Kolpin, S. J. Larson. 1999. Testing water quality for pesticide pollution. Environmental Science and Technology 33/7: 164-169.

Henry, M. et al. 2012. A common pesticide decreases foraging success and survival in honeybees. Science 336/6079: 348-350.

Hickey, J. J., D.W. Anderson. 1968. Chlorinated hydrocarbons and eggshell changes in raptorial and fish-eating birds. Science 162/3850: 271-273.

Jelks, H. L. et al. 2008. Conservation status of imperiled North American freshwater and diadromous fishes. Fisheries 33/8: 372-407.

Johnson, R. C., R. J. Williams. 2004. A model to estimate influent and effluent concentrations of estradiol, estrone, and ethinylestradiol at sewage treatment works. Environmental Science and Technology 38/13:3649-3658.

Khot, L. R. et al. 2012. Applications of nanomaterials in agricultural production and crop protection: A review. Crop Protection 35: 64-70.

Kidd, K. A. et al. 2007. Collapse of a fish population after exposure to a synthetic estrogen. Proceedings of the National Academy of Sciences 104/2: 8897-8901.

Kolkwitz, R., M. Marsson. 1909. Oekologie der tierischen Saprobien. Internationale Revue der gesamten Hydrobiologie 2: 126-152.

Kortenkamp, A., T. Backhaus, M. Faust. 2009. State of the art report on mixture toxicity. Final report. http://ec.europa.eu/environment/chemicals/pdf/ report_Mixture\%20toxicity.pdf (accessed August 23, 2012).

Kramer, V.J. et al. 2011. Adverse outcome pathways and ecological risk assessment: Bridging to population-level effects. Environmental Toxicology and Chemistry 30/1: 64-76.

Kuivila, K. M., M. L. Hladik. 2008. Understanding the occurrence and transport of current-use pesticides in the San Francisco Estuary Watershed. San Francisco Estuary and Watershed Science 6/3: article 2. http://repositories. cdlib.org/jmie/sfews/vol6/iss3/art2 (accessed August 18, 2012).

Langston, N. 2012. Rachel Carson's legacy: Endocrine dis rupting chemicals and gender concerns. GAIA 21/3: 225-229.

Liess, M., R. B. Schaefer, C. A. Schriever. 2008. The footprint of pesticide stress in communities: Species traits reveal community effects of toxicants. Science of the Total Environment 406/3: 484-490.

Martinovic, D., W. T. Hogarth, R. E. Jones, P.W. Sorensen. 2007. Environmental estrogens suppress hormones, behavior, and reproductive fitness in male fathead minnows. Environmental Toxicology and Chemistry 26/2: 271-278.

Mauch, C. 2012. Der Mensch als Gast der Borgias. Rachel Carsons Silent Spring aus historischer Sicht. GAIA 21/3: 230-231.

Meek, M. E., A. R. Boobis, K. M. Crofton, G. Heinemeyer, M.van Raaij, C. Vickers. 2011. Risk assessment of combined exposure to multiple chemicals: A WHO/ IPCS framework. Regulatory Toxicology and Pharmacology 60: S1-S14.

Newman, M.C., M. A. Unger. 2003. Fundamentals of ecotoxicology. Boca Raton, FL: CRC Press.

Regulation (EC) No 1107/2009. 2009. Regulation (EC) No 1107/2009 of the European Parliament and of the Council of 21 October 2009 conceming the placing of plant protection products on the market. Official Journal of the European Union L 309: 1-50.

Sandahl, J. F., D. H. Baldwin, J. J. Jenkins, N. L. Scholz. 2007. A sensory system at the interface between urban stormwater runoff and salmon survival. Environmental Science and Technology 41/8: 2998-3004.

Scheringer, M. 2012. Umweltchemikalien 50 Jahre nach Silent Spring: ein ungelöstes Problem. GAIA 21/3: 210-216.

SETAC (Society of Environmental Toxicology and Chemistry). 2011. Summary of the SETAC Pellston workshop on pesticide risk assessment for pollinators. Pensacola, FL: SETAC.

Shugart, L. R. 1995. Environmental genotoxicology. In: Fundamentals of aquatic toxicology. Edited by G. M. Rand. Bristol, PA: Taylor and Francis. 405-419.

Stockholm Convention. 2004. Stockholm Convention on persistent organic pollutants. www.pops.int (accessed August 18, 2012).

Sumpter, J.P. 2005. Endocrine disrupters in the aquatic environment: An overview. Acta Hydrochimica Hydrobiologica 33/1: 9-16.

UNEP (United Nations Environment Programme). 2010. UNEP emerging issues: Global honeybee colony disorder and other threats to insect pollinators. Nairobi: UNEP.
UNEP, AMAP (Arctic Monitoring and Assessment Programme). 2011. Climate change and POPs: Predicting the impacts. Report of the UNEP/AMAP expert group. Geneva: Secretariat of the Stockholm Convention.

US DOI (U.S. Department of the Interior, Fish and Wildlife Service). 2009. Endangered and threatened wildlife and plants; removal of the brown pelican (Pelecanus occidentalis) from the Federal List of Endangered and Threatened Wildlife. Federal Register 74/220: 59444-59472.

Van Aggelen, G. et al. 2010. Integrating omic technologies into aquatic ecological risk assessment and environmental monitoring: Hurdles, achievements, and future outlook. Environmental Health Perspectives 118/1: 1-5.

Van der Oost, R., J. Beyer, N.P. E. Vermeulen. 2003. Fish bioaccumulation and biomarkers in environmental risk assessment: A review. Environmental Toxicology and Pharmacology 13/2: 57-149.

Vos, J.G. et al. 2000. Health effects of endocrine-dis rupting chemicals on wildlife, with special reference to the European situation. Critical Reviews in Toxicology 30/1: 71-133.

Walker, C.H., S. P. Hopkin, R. M. Sibly, D. B. Peakall. 2001. Principles of ecotoxicology. $2^{\text {nd }}$ edition. London: Taylor and Francis.

Water Quality Act. 1965. An Act to amend the Federal Water Pollution Control Act to establish a Federal Water Pollution Control Administration, to provide grants for research and development, to increase grants for construction of sewage treatment works, to require establishment of water quality criteria, and for other purposes. Public Law 89-234, October 2, 1965. United States Statutes at Large 79: 903.

Weis, J. S., P. Weis. 1995. Effects of embryonic exposure to methylmercury on larval prey-capture ability in the mummichog, Fundulus heteroclitus. Environmental Toxicology and Chemistry 14/1: 153-156.

Werner, I., K. Moran. 2008. Effects of pyrethroid insecticides on aquatic organisms. In: Synthetic pyrethroids: Occurrence and behavior in aquatic environments. Edited by J. Gan et al. American Chemical Society (ACS) Symposium Series 991. Washington, D.C.: ACS. 310-335.

Weston, D. P., R. W. Holmes, J. You, M. J. Lydy. 2005. Aquatic toxicity due to residential use of pyrethroid insecticides. Environmental Science and Technology 39/24: 9778-9784.

WFD (Water Framework Directive). 2000. Directive 2000/60/EC of the European Parliament and of the Council of 23 October 2000 establishing a framework for Community action in the field of water policy. Official Journal of the European Union L 327: 1-73.

Wikipedia. 2011. Ecotoxicology. http://en.wikipedia.org/wiki/Ecotoxicology (accessed October 28, 2011).

Winston, M. L. 1999. Nature wars: People vs. pests. $3^{\text {rd }}$ edition. Cambridge, MA: Harvard University Press. accepted July 16, 2012

Inge Werner

Born 1957 in Bräunlingen, Germany. PhD 1995. 1996 to 2010 research in aquatic toxicology at the University of California

in Davis, USA. Since 2010 head of the Swiss Centre for Applied Ecotoxicology located at Eawag, Dübendorf, and the École Polytechnique Fédérale de Lausanne (EPFL).

Areas of expertise: biomarkers and detection of pollutant effects in aquatic organisms, with emphasis on the sub-lethal effects of insecticides.

Bettina Hitzfeld

Born 1961 in Luxembourg, Luxembourg. PhD 1991. Since $\mathbf{2 0 0 2}$ at the Swiss Federal Office for the Environment, Bern, and since 2007 head of the Section Biocides and

Plant Protection Products. Areas of expertise: risk assessment of biocides and plant protection products,

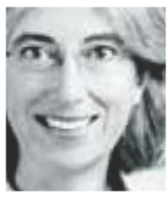
ozone depleting substances, synthetic climate change gases, multilateral environmental agreements. 